\title{
Implementation of Fuzzy Logic Method for Lifting Control System on Autonomous Underwater Vehicles
} Ahmad ZARKASI $^{1 *}$, Rossi PASARELLA ${ }^{2}$, Siti NURMAINI ${ }^{3}$, Muhammad MAULANA $^{4}$,

\author{
and Muhammad FAJAR ${ }^{5}$
}

\author{
${ }^{I}$ zarkasi98@gmail.com, Robotics and Control System Research Group Faculty of Computer Science \\ Universitas Sriwijaya, Palembang, Indonesia \\ ${ }^{2}$ passarella.rossi @gmail.com, Robotics and Control System Research Group Faculty of Computer Science, Universitas \\ Sriwijaya, Palembang, Indonesia \\ ${ }^{3}$ sitinurmaini@gmail.com, Robotics and Control System Research Group Faculty of Computer Science, Universitas \\ Sriwijaya, Palembang, Indonesia \\ ${ }^{4}$ maulana370maulana@gmail.com, Robotics and Control System Research Group Faculty of Computer Science, Universitas \\ Sriwijaya, Palembang, Indonesia \\ ${ }^{5}$ fajarcrzcrz@gmail.com, Robotics and Control System Research Group Faculty of Computer Science, Universitas Sriwijaya, \\ Palembang, Indonesia \\ *Corresponding author: zarkasi98@gmail.com
}

\begin{abstract}
The AUV navication system can move autonomously in water using various methods. the implementation of lifting control system at AUV is needed to maintain the stability of the AUV when lifting under water. In this paper, the lifting process of AUV uses the fuzzy method. The fuzzy method is used for rule-based decision-making in solving problems, which are made in simulation on the program. AUV has 2 sonar sensors, which are located on the front and the part is located at the rear. Sonar sensors are useful for knowing there are obstacles under AUV. Furthermore, the input will be processed into the microcontroller using the fuzzy method and the output of the microcontroller will produce a PWM value that will regulate the speed of the motor. The distance of the sensor testing starts from $30 \mathrm{~cm}$ which is a minimum distance of up to $150 \mathrm{~cm}$ which is the maximum distance, with 25 rule bases. the results obtained are in accordance with the system designed.

Keywords: $A U V$, lifting control system, fuzzy logic
\end{abstract}

\section{INTRODUCTION}

AUV is an underwater vehicle that moves autonomously, while the ROV is an underwater vehicle driven by a remote control from above the water surface [1]. With the underwater vehicles that can dive we can make underwater observations that have several risks, namely the existence of areas that are difficult to reach humans, waters exposed to toxic waste, limited oxygen, the occurrence of hydrostatic pressure on the body of divers, and high risk due to attacks wild animals [2]. To overcome this problem, using a method will be very necessary, one of which is the Fuzzy Logic method.

In the real world underwater vehicles when operating must face waves of seawater so that when walking underwater vehicles must shake. Therefore an underwater vehicle must be stable or maintain its position while operating under the sea so that no accident occurs [1] [2]. Not only maintaining stability but knowing the position and environment are prerequisites of AUV. Localization errors can cause mission failure, damage or even loss of AUV. By using sonar sensors we can find out what is underwater. The main aspect of monitoring the marine environment is detecting and measuring.

Fuzzy method is a rule-based decision-making process that aims to solve problems, where the system is difficult to model or there is an abundance of ambiguity and obscurity. Implication of lifting control system using fuzzy will be very helpful. Underwater vehicles must be stable or maintain their position when operating under the sea so that accidents do not occur [3] [4]. Sonar sensors use acoustic signals, therefore the underwater sensors used are sonar sensors [5] [6]. In this study fuzzy sugo method is used on AUV for lifting control system. Sonar sensor is used to determine the distance under AUV by lifting.

\section{METHOD}

\section{A. Fuzzy Logic}

in 1965 the theory of fuzzy sets was first put forward by Lotfi A. Zadeh, a professor of computer science at the University of California, Berkeley, United States in a paper entitled 'Fuzzy Sets" [3]. According to Asus Naba, fuzzy logic is: "A methodology to calculate linguistic variables instead of counting numbers. Words used in fuzzy logic are not as precise as numbers, but words are much closer to human intuition. In general, the concept of fuzzy methods includes firm sets, fuzzy sets, fuzzy membership, linguistic variables, basic operations, and fuzzy rules [4]. Figure 1 below is the architecture of the fuzzy logic.

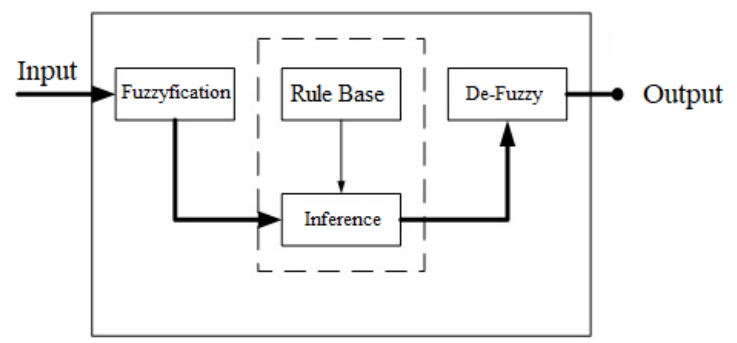

Figure1. Architecture of Fuzzy logic 
The membership function is a function that is used to map each crips $x$ value to a membership level in intervals (0.1). for example, in the function of this triangle there is also only one value of $\mathrm{x}$ which has a degree of membership equal to 1 , namely $\mathrm{x}=\mathrm{b}$. However, the values around $\mathrm{b}$ have a membership degree that drops quite sharply (away from the value of 1). The membership function for the triangle curve is shown in equation 1 ,

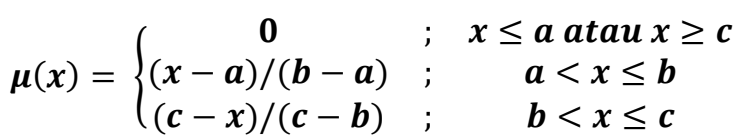

\section{B. Sonar System}

The sonar system uses the MB7060 XL-Maxsonar - WR1 sensor. This sensor serves to detect the distance in water, in contrast to an ultrasonic sensor that cannot be used in the water because ultrasonic sound waves can only propagate in the air while sonar is designed to propagate in the water [6]. AUV has 2 sonar sensors located at the bottom, 1 is located at the front and 1 is located at the rear.The distance value obtained by the sonar sensor will be used as input to the fuzzy process. The sonar sensor will emit waves after a wave hits an object, the wave will be reflected back and received by the sonar sensor. Here is the flow chart of the sonar sensor in the figure 2 .

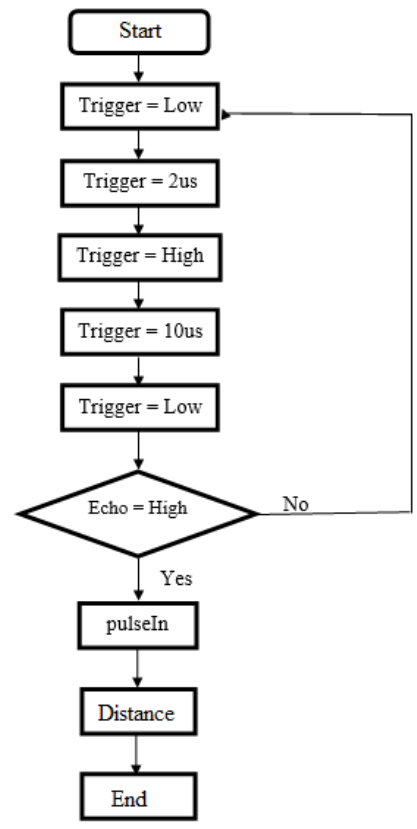

Figure 2. framework Sonar system

In robotics, sonar sensors have three different, but related, goals: 1. As Obstacle Avoidance is the first sensor to emit an acoustic signal within a certain vulnerable time if it hits an object then the signal will be reflected back by an echo (echo signal) and received by the sensor at that vulnerable time that will be processed into a distance. Robots use this information to plan trajectories around obstacles and prevent collisions [5][8].

2. As a sonar mapping (Sonar Mapping) are some echo signals (echoes) obtained from around search or from several sonar sensors used to construct environmental maps. As with radar displays, one dot is placed within the detected range[5][8].
3. As an object recognition is a sequence of echo signals or sonar mapping is processed to classify the echo signal, then used to describe the structures of the detected object. If successful, this information will be useful for robot navigation [5][8].

\section{Underwater Robotic}

AUV is a computer-controlled robot, moving underwater without requiring input from the operator. AUV is known as Unmanned Undersea Vehicles (UUVs). In military applications, AUV is more commonly referred to as an Unmanned Underwater Vehicle (UUV) or unmanned underwater vehicle, but unmanned does not mean automatic. In its application AUV contributes to the military, industry and academic research. Research and development of AUVs have become a popular topic in modern robotics. The AUV project has reached a number of maritime areas such as maritime security, oceanography. The main objective of this project is to implement robot automation to conduct reconnaissance missions as directed by human operators [7].

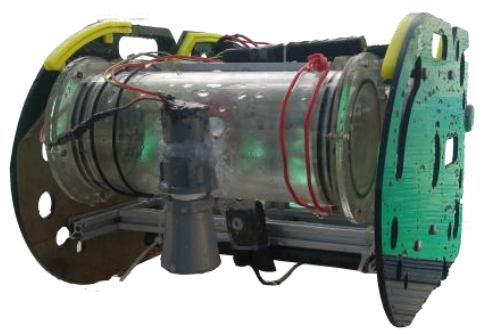

Figure 3. Autonomous Underwater Vehicles

To achieve this, AUV must be able to read and understand the mission ordered by the operator through simple instructions similar to human verbal commands, carrying out certain missions, collecting data and reporting back to the operator. AUV requires sensing systems such as cameras to determine the direction and position of targets.

\section{LIFTING CONTROL SYSTEM DESIGN}

\section{A. Hardware Desing}

Hardware design is a component of the AUV system builder which consists of the design phase and the system design. In the system design consists of several stages, namely, ballast tank system design, sonar sensor design, minimum system design and DC motor design. AUV has a length of 49 $\mathrm{cm}$, width $40 \mathrm{~cm}$, height $36 \mathrm{~cm}$ and weighs $9 \mathrm{~kg}$

The design concept is the constituent components of the AUV that will be created. Lifting control system has 3 components, namely input, process and output. The following is a system design concept that is made, can be seen in Figure 4.

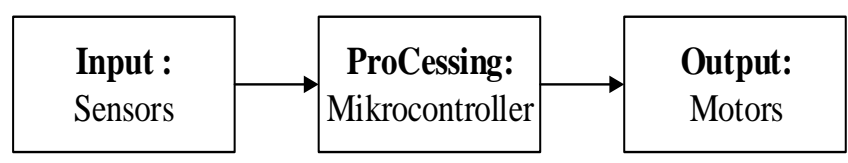

Figure 4. Diagram block system 
The sonar sensor is located at the front of the AUV to detect obstacles under the AUV. Furthermore, the input will be processed to the microcontroller using fuzzy logic and the microcontroller output will produce a PWM value that will regulate the speed of the motor.

\section{B. Fuzzy Desing}

The fuzzification process on the AUV system consists of two inputs to the sonar sensor reading area, the upper and lower front. The minimum distance used by the sensor is $50 \mathrm{~cm}$ and the maximum distance used by the $3000 \mathrm{~cm}$ sensor with five linguistic variables namely, very close, close, normal, far and very far away. The following is the fuzzification membership function can be seen in Figure 4.

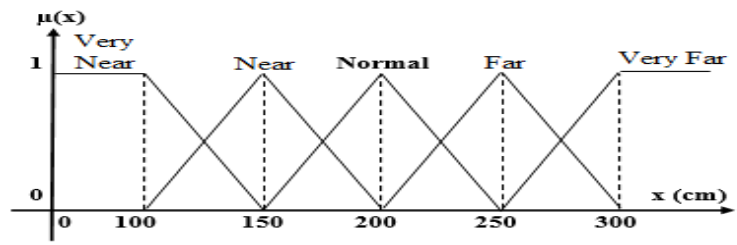

Figure 5. Membership function

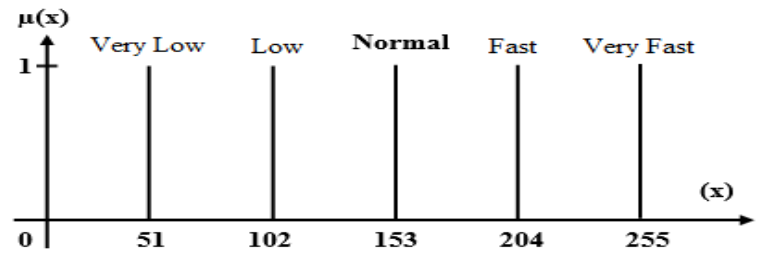

Figure 6. Singleton Function
The following shows the linguistic variables of DC motor output in Figure 5.The input to the rule base is the distance from two sonar sensors with the upper and front front reading areas using five linguistic variables which means there are 25 rule bases. To get fuzzy output based on the rule base that the author has made above, the Sugeno method will be used in designing Fuzzy Inference. After determining the rule base, fuzzy sugo inference will be made using the max operation min.

\section{RESULTS AND ANALYSIS}

\section{A. Sonar Testing}

In testing the sonar sensor the distance data will be taken using an obstacle placed in front of the sensor, the output used on this sonar sensor is an analog voltage. The output (output) of the sensor will be converted using the ADC which will be connected to the ADC pin (port F) on the microcontroller with a data width of 10 bits. The minimum reading distance on the sensor is $20 \mathrm{~cm}$ and the maximum sensor distance is $765 \mathrm{~cm}$, therefore the microcontroller uses a 10-bit data width, a 10-bit conversion that is from 0 decimal to 1023 decimal

Testing on the sonar sensor is to find out whether the sonar sensor is functioning properly or not. Tests on the proximity sensor using obstacles that will be placed at a distance - the distance to be tested. The distance tested is $30 \mathrm{~cm}$ which is a minimum distance of up to $150 \mathrm{~cm}$ which is the maximum distance. Here are the results of sensor testing on land in Table 1 and Table 2.

Table 1. Sensor Testing Data

\begin{tabular}{|c|c|c|c|c|c|c|c|c|c|}
\hline \multirow{2}{*}{$\begin{array}{c}\text { Distance } \\
(\mathrm{cm})\end{array}$} & $\begin{array}{c}\text { ADC } \\
\text { Calculation }\end{array}$ & \multicolumn{2}{|c|}{ ADC Result } & $\begin{array}{c}\text { Distance } \\
\text { Results } \\
(\mathrm{cm})\end{array}$ & \multicolumn{2}{|c|}{$\begin{array}{c}\text { Error ADC } \\
(\%)\end{array}$} & \multicolumn{2}{|c|}{$\begin{array}{c}\text { Error } \\
\text { Distance } \\
(\%)\end{array}$} \\
\cline { 3 - 10 } & & S1 & S2 & S1 & S2 & S1 & S2 & S1 & S2 \\
\hline 30 & 39 & 39 & 39 & 30 & 30 & 0 & 0 & 0 & 0 \\
\hline 50 & 66 & 63 & 63 & 47 & 47 & 4.5 & 4.5 & 6 & 6 \\
\hline 70 & 93 & 91 & 90 & 68 & 67 & 2.1 & 3.2 & 2.8 & 4.2 \\
\hline 90 & 119 & 119 & 119 & 89 & 89 & 0 & 0 & 1.1 & 1.1 \\
\hline 110 & 146 & 142 & 142 & 106 & 106 & 2.7 & 2.7 & 3.6 & 3.6 \\
\hline 130 & 172 & 168 & 167 & 127 & 127 & 2.3 & 2.9 & 2,3 & 2.3 \\
\hline 150 & 199 & 194 & 192 & 146 & 147 & 2.5 & 3.5 & 2.6 & 2 \\
\hline
\end{tabular}


Table 2. Sonar Distance

\begin{tabular}{|c|c|c|c|c|c|}
\hline NO & $\begin{array}{c}\text { Distance } \\
(\mathrm{cm})\end{array}$ & $\begin{array}{c}\text { Sonar 1 } \\
\text { Distance } \\
(\mathrm{cm})\end{array}$ & $\begin{array}{c}\text { Sonar 2 } \\
\text { Distance } \\
(\mathrm{cm})\end{array}$ & $\begin{array}{c}\text { Error } \\
\text { Sensor 1 } \\
(\%)\end{array}$ & $\begin{array}{c}\text { Error } \\
\text { Sensor 2 } \\
(\%)\end{array}$ \\
\hline 1 & 30 & 33 & 32 & 10 & 6.6 \\
\hline 2 & 50 & 54 & 52 & 8 & 4 \\
\hline 3 & 60 & 60 & 62 & 0 & 3.3 \\
\hline 4 & 70 & 67 & 67 & 4.2 & 4.2 \\
\hline 5 & 100 & 104 & 98 & 4 & 2 \\
\hline 6 & 110 & 78 & 76 & 29 & 30 \\
\hline 7 & 150 & 114 & 110 & 24 & 26 \\
\hline
\end{tabular}

Sonar sensor distance testing, starting at a distance of 30. At this distance sonar sensor readings range from $33 \mathrm{~cm}$ and $32 \mathrm{~cm}$. This value is included in the category of good temporary value. Then proceed with the farthest sensor distance testing which is $150 \mathrm{~cm}$. As a result, the sornar reading value was $114 \mathrm{~cm}$ and $110 \mathrm{~cm}$. The value is far enough in the category of tolerance, because the error is above $10 \%$. So that the sonar sensor works well, in the range of $30 \mathrm{~cm}$ to $100 \mathrm{~cm}$.

\section{B. PWM Testing}

Testing on DC motors is to find out whether the motor is functioning properly or not. In testing motor 1 and 2 , a calibration was performed to get the same speed on motor 1 and motor 2. The first was tested with a PWM value of 255 on each motor, after which the voltage obtained on motor 1 was $6.83 \mathrm{~V}$ and the voltage on motor 2 was $6.79 \mathrm{~V}$. Second, the lowest voltage value is taken at each motor to determine the value to be taken as a reference to the speed of the motor to be used. Third, re-testing the motor 1 , because motor 1 has a greater voltage value on motor 2 .

After repeated testing, the voltage value obtained at motor 1 is $6.79 \mathrm{~V}$ when the PWM value is 253 . So the PWM calibration value obtained at motor 1 is 253 and motor 2 is 255 . Here are the results of PWM testing on land in Table 3 and Table 4

Table 3. PWM Testing 1

\begin{tabular}{|c|c|c|c|c|c|}
\hline \multicolumn{5}{|c|}{ Motor 1 } \\
\hline No & PWM REff & Vref & Vin & $\begin{array}{c}\text { the calculation results } \\
\text { PWM }\end{array}$ & Error (\%) \\
\hline 1 & 255 & 11.20 & 9.30 & 211 & 17,2 \\
\hline 2 & 230 & 11.20 & 8.99 & 204 & 11,3 \\
\hline 3 & 196 & 11.20 & 8.53 & 194 & 1 \\
\hline 4 & 176 & 11.20 & 8.20 & 186 & 11,8 \\
\hline 5 & 160 & 11.20 & 7.89 & 179 & \\
\hline
\end{tabular}

Table 4. PWM Testing 2

\begin{tabular}{|c|c|c|c|c|c|}
\hline \multicolumn{5}{|c|}{ Motor 2 } \\
\hline No & PWM Reff & Vref & Vin & $\begin{array}{c}\text { the calculation results } \\
\text { PWM }\end{array}$ & Error (\%) \\
\hline 1 & 255 & 11.20 & 9.33 & 212 & 16,8 \\
\hline 2 & 225 & 11.20 & 9.08 & 204 & 9,3 \\
\hline 3 & 200 & 11.20 & 8.79 & 200 & 0 \\
\hline 4 & 186 & 11.20 & 8.61 & 196 & 18,6 \\
\hline 5 & 150 & 11.20 & 7.82 & 178 & \\
\hline
\end{tabular}




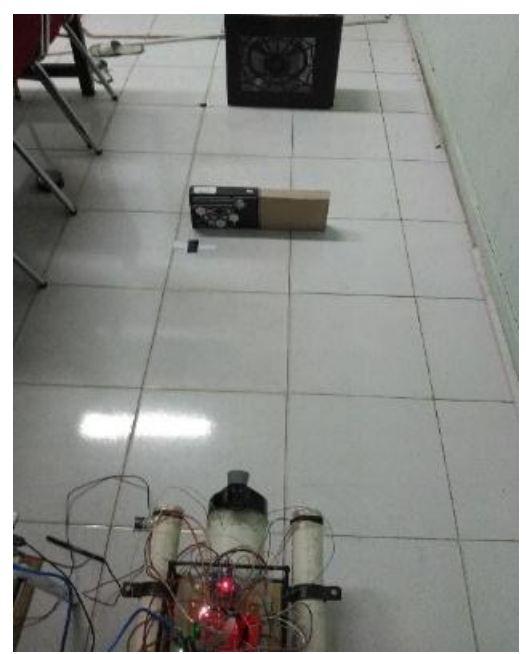

\section{Fuzzy Logic Testing}

Fuzzy logic testing is carried out in two parts, namely real testing and simulation. Real penguian is done using a microcontroller on ROV, while testing with simulations using MATLAB software. The following are the results of the program using the arduino which will be displayed using $C$ \# and MATLAB can be seen in Table 3 .

In table 3 , the test is done 25 times with different sensor data values. The test aims to compare the measurement value with the value of the overall simulation results. If the data is analyzed further, then the comparison of these values is quite significant and certainly far from the word success. But real testing is carried out in water, which has a period of water and also wave propagation in the water. While testing is simulated, only based on the input provided with the ideal value.

Figure 4. ROV testing

Table 5. Fuzzy Logic Testing

\begin{tabular}{|c|c|c|c|c|c|c|}
\hline No & Sensor 1 & Sensor 2 & Program & Matlab & Manual & Explanation \\
\hline 1 & 110 & 140 & 61 & 59 & 61 & Up, Very Slow \\
\hline 2 & 121 & 160 & 72 & 72 & 72 & Up, Very Slow \\
\hline 3 & 139 & 232 & 88 & 90 & 88 & Up, Very Slow \\
\hline 4 & 142 & 277 & 90 & 93 & 90 & Up, Very Slow \\
\hline 5 & 148 & 298 & 99 & 100 & 99 & Up, Very Slow \\
\hline 6 & 134 & 111 & 63 & 58 & 63 & Up, Very Slow \\
\hline 7 & 148 & 133 & 84 & 83 & 84 & Up, Very Slow \\
\hline 8 & 156 & 223 & 111 & 108 & 111 & Up, Slow \\
\hline 9 & 179 & 277 & 130 & 132 & 130 & Up, Slow \\
\hline 10 & 186 & 288 & 138 & 139 & 138 & Up, Slow \\
\hline 11 & 195 & 134 & 85 & 85 & 85 & Up, Very Slow \\
\hline 12 & 202 & 169 & 121 & 121 & 121 & Up, Slow \\
\hline 13 & 212 & 198 & 150 & 151 & 150 & Up, Normal \\
\hline 14 & 228 & 267 & 181 & 182 & 181 & Down, Normal \\
\hline 15 & 237 & 256 & 190 & 191 & 190 & Down, Normal \\
\hline 16 & 241 & 119 & 70 & 70 & 70 & Up, Very Slow \\
\hline 17 & 252 & 166 & 118 & 118 & 118 & Up, Slow \\
\hline 18 & 265 & 236 & 189 & 190 & 189 & Down, Normal \\
\hline 19 & 271 & 270 & 224 & 213 & 224 & Down, Fast \\
\hline 20 & 275 & 299 & 229 & 229 & 229 & Down, Fast \\
\hline 21 & 278 & 132 & 82 & 83 & 82 & Up, Very Slow \\
\hline 22 & 282 & 173 & 125 & 125 & 125 & Up, Slow \\
\hline 23 & 288 & 210 & 163 & 163 & 163 & Down, Normal \\
\hline 24 & 294 & 277 & 231 & 228 & 231 & Down, Fast \\
\hline 25 & 298 & 300 & 252 & 253 & 252 & Down, Very Fast \\
\hline
\end{tabular}

Therefore, the results obtained will also be very different. From the data also obtained testing has a very small difference between program testing, simulation and manual calculation. Based on these three values, it can be interpreted that the system created and implemented has worked well.

\section{CONCLUSION}

Overall the system has worked well according to what is expected. Testing with measurements for both sensors has good data. Likewise with simulation measurements, both using programs and manually. The results obtained are not much different, it can even be said to be close to the same. The error value from the measurement of sensor data is still below the tolerance of $10 \%$ for distances below $100 \mathrm{~cm}$, while the data for above $100 \mathrm{~cm}$ the value of tolerance is above $10 \%$. This percentage shows that the underwater robot's automatic navigation system shows that it works well and correctly with a large degree of accuracy. 


\section{ACKNOWLEDGMENT}

This work was supported by The Faculty of Computer Science, Universitas Sriwijaya, Indonesia and Robotic and Control System Research Group faculty of Computer Science Universitas Sriwijaya, Palembang, Indonesia.

\section{REFERENCES}

[1] Ahmad Zarkasi, et al, 2018, “ Implementation Color Filtering and Harris Corner Method on Pattern Recognition System for Underwater Objects", Journal of Computer Engineering and Applications Vol. 6, No. 3.

[2] Siti Nurmaini, Zarkasi Ahmad, 2015. "Simple Pyramid RAM-Based Neural Network Architecture for Localization of Swarm Robots". Jurnal of Information Processing Systems, Vol.11, No.3, pp.370 388, September 2015.

[3] K. Siantidis, 2016. "Side Scan Sonar Based Onboard SLAM System for Autonomous Underwater Vehicles,” IEEE J. Ocean. Eng., pp. 195-200.

[4] Y. Chandra, D. S. Purnomo, and E. Suryawati, "Rancang Bangun Sistem Ballast pada ROV (Remotely Underwater Vehicle)". Institut Teknologi Sepuluh

November, 2011

[5] D. P. Sinaga, E. Susanto, and R. Nugraha, 2016," Rancang Bangun Kestabilan Posisi Sistem Kendali Manual Robot Kapal Selam Menggunakan Metode Fuzzy Logic”. Universitas Telkom, 2016.

[6] M. N. Fauzi, 2009," Sistem Navigasi pada Wahana Bawah Air Tanpa Awak “. Institut Teknologi Sepuluh November, 2009.

[7] F. Khairan, J. Dharma, and S. M. Ariyanto, "Model Nonlinear Pada Autonomous Underwater Vehicle (Auv)," pp. 1-6, 2011.

[8] K. Siantidis, "Side Scan Sonar Based Onboard SLAM System for Autonomous Underwater Vehicles," IEEE J. Ocean. Eng., pp. 195-200, 2016 